\title{
(Preprint)
}

\section{Why are Euro ELF (English as a lingua franca) user attitudes ambivalent? Pre-service teachers from Spain and Sweden}

\author{
Hyeseung Jeong, University West, Sweden \\ Raquel Sánchez Ruiz, University of Castilla-La Mancha, Spain \\ Georgia Wilhelmsson' University West, Sweden
}

\begin{abstract}
English as a lingua franca, or ELF is a well-known concept referring to English used as a contact language among people from different linguistic backgrounds. ELF users are thus people using English as ELF. This study investigated the ELF user attitudes of pre-service teachers from Spain and Sweden, towards English and its users. From the convergences and divergences of their attitudes, it emerged that the ELF user attitudes of the two European student cohorts tended to be ambivalent, mixed, and self-contradictory. After discussing factors for participants' attitudinal tendencies, we conclude that the ambivalence in their overall attitudes seem to mirror the ambivalence of the 'double' definitions of English in policy documents, which are largely incompatible in setting the goals of teaching and learning the language. We suggest that university teaching help pre-service teachers experience real-life use of English and critically engage with policy documents for future teaching practices.
\end{abstract}

Keywords: English as a lingua franca (ELF), ELF users, ELF user attitude, ambivalence in ELF user attitudes, ambivalence in language policies, pre-service teacher education

\section{Introduction}

$E L F$, the acronym of English as a lingua franca, has become an established concept that refers to English used as a contact language among people from different linguistic backgrounds, 'detached from its historical home' and transcending national boundaries (Cogo and Jenkins 2010, 271). ELF users, the concept central to this study, are thus 
people using English as ELF, that is, for international or transnational communication. This definition of ELF user is centrally concerned with how and with whom people use English rather than whether they know the concept of ELF or consider themselves ELF users. Many citizens of the European Union (EU) countries can be typical ELF users, as they mainly use English with people from other European countries or other continents in various social milieus (Seidlhofer 2020) - from political summits to the Eurovision Song Contest.

Substantial research in various geographical contexts has investigated attitudes of university students (often pre-service English teachers) and English teachers, who can be framed as 'ELF users' according to our criteria (e.g., Cogo 2010; Curran and Chern 2017; Dewey and Pineda 2020; Jenkins 2007; Sung 2018; Takahashi 2017; Rahatlou, Fazilatfar, and Allami 2018; Sung 2018; Jaramillo, Dávila, and Jarquín, 2020; Lai 2020). While some studies in this body of research found that pedagogical intervention foster positive attitudes towards English as ELF (e.g., Chacón-Beltrán 2021; DelgadoMarín 2018; Dewey and Pineda 2020), many report that ELF user attitudes are usually not straightforward but rather ambivalent, mixed, inconsistent, and often selfcontradictory. Particularly, as Sung (2018) reports in a university context in Hong Kong, ELF users often note that native speakers may not need to be the model for learners; however, they also believe there should be some type of 'standard' for using English internationally.

In our study, we investigate the ELF user attitudes of pre-service teachers from Spain and Sweden - a showcase of Euro ELF users and their attitudes - after their online collaboration. We will focus on the extent to which the attitudinal tendencies among ELF users reported in previous research are present in the convergences and divergences of the two European student cohorts' attitudes. The findings will be 
discussed in relation to some individual, policy and educational factors, whereby we will suggest what university teaching can do for future English teachers and their learners, 'who naturally become ELF users' outside the classroom (Siqueira 2020, 1).

\section{Background}

\section{Ambivalence in ELF user attitudes}

Ambivalence in the attitudes of people using English as ELF is 'multiplicity of voices, styles and perspectives' (Sung 2018, 43), often connected to the issues of whether to set native speakers (NS) as language learning models and/or whether 'standard' forms are necessary for ELF communication (Jenkins 2007). Some studies report contrasting attitudes between groups of people. For example, Curran and Chern (2017) documented that, in a Taiwanese university context, interns and English majors in Taiwan favoured acquiring native-like proficiency while English minors relied less on NS models in view of the need for adapting to a variety of English users.

However, ambivalence in ELF user attitudes is more frequently manifested as being 'ambiguous, self-contradictory, and inconsistent' (Sung 2018, 43; also see Jenkins 2007; Takahashi 2017; Rahatlou et al. 2018; Jaramillo et al. 2020; Lai 2020). In Sung (2018), for example, university students in Hong Kong were of the opinion that sounding like a native speaker is not necessary for effective ELF communication, but they still tended to believe that there must be a 'standard' for mutual intelligibility among ELF users. In Jaramillo et al. (2020), international pre-service teachers in a master's program in the US clearly showed awareness of ELF and diverse English varieties, asserting that intelligibility is more relevant than grammar accuracy to effective ELF communication. However, the same participants also aspired to be nativelike for their own proficiency including pronunciation, idiomaticity and lexical 
repertoire. Likewise, in Lai (2020), many English teacher trainees in Hong Kong were confident about their own accents and showed positive attitudes towards speakers from different backgrounds; however, they still displayed a strong preference for American and British English. Similarly, in Rahatlou et al. (2018), in-service English teachers in Iran shared that they focus on intelligibility rather than nativeness in teaching pronunciation. They also argued for non-native speakers' (NNS) authority over their own English, as well as for the legitimacy of different varieties. Nevertheless, the teachers also showed the tendency of wanting to conform to NS norms. In Takahashi (2017), teacher and learner participants, took it for granted that 'standard' NS English is presented as the target model in coursebooks although most of the participants agreed on the importance of introducing 'other' varieties given that ' $[\mathrm{t}]$ here are many kinds of English used in the world' (46).

\section{Ambivalence in language policies and English education: Zooming into Europe}

The ambivalence in ELF user attitudes reviewed above probably involves feeling confused and uncertain about the mismatch between what is taught in the English classroom and what is needed in the real-life use of English (Rose, McKinley, and Galloway 2020). That is, English education has traditionally focused on NS norms, especially British and American norms, while most English learners would need, and use English as 'ELF' (Jeong 2021; Siqueira 2020).

In Europe, such a mismatch between English education and real-life use of the language seems connected largely to the ambivalent double definitions of the English language in policy documents. On the one hand, for example, the national syllabus for English education in Sweden highlights the importance of global/international perspectives, 'moving beyond the British and American perspectives that have traditionally held 
sway' in the country (Hult 2017, 277). Likewise, Spain emphasizes the importance of English education in view of its role as an international language or lingua franca 'in a wide range of contexts, notably including continental Europe' (Reichelt 2006, 3; Caraker 2016). This recognition of the internationality of English, which is in fact the reason that most European youths learn the language as a compulsory school subject (Pew Research Center 2020), is expected to have practical implications for English education through promoting skills and competences needed for using the language in international contexts, skills and competences certainly different than 'nativeness' or ‘native-likeness' (Cogo and Jenkins 2010; Jeong 2021; Hynninen 2014).

On the other hand, however, by applying to English education the Common European Framework of Reference for Languages (CEFR) (Council of Europe [2001] 2020), the EU guidelines for foreign language education, Sweden and Spain, like other European countries, also define English as a foreign language (EFL) associated with the countries speaking the language as their mother tongue, such as the UK and the US (Cogo and Jenkins 2010; Hynninen 2014). With this conceptualisation of English as a foreign language, NS norms can be unproblematically implemented, the emphasis of teaching the language as a lingua franca can easily be compromised or diminished, and the objectives of learning English become ambiguous. By acknowledging the controversies of setting native speaker competence and culture as the goal of language learning (see Cogo and Jenkins, 2010; Hynninen 2014; McNamara 2011), and perhaps as an impact of Brexit, the Council of Europe removed the phrase 'native speakers' from the proficiency descriptors in the 2020 CEFR Companion Volume (Council of Europe [2001] 2020, 24). However, with its demand on 'correctness', the CEFR has become more ambiguous and is even 'suspicious' of still attaching to native speaker norms without using the phrase 'native speakers'. For example, in the section 'Grammatical 
accuracy', the 2020 volume states, 'This scale concerns both the user/learner's ability to recall "prefabricated" expressions correctly [author emphasis]' (132). 'Correctness' makes sense only if there exist references or criteria for being 'correct' or 'incorrect'; second language English users, irrespective of the presence of native speakers, tend to bring in native speaker norms when 'correctness' is concerned (Hynninen 2014). Thus, English education guided by the CEFR still likely mismatches the needs of European learners of English, for most of whom what is important is to achieve clarity in content and intent rather than using 'correct' grammar (Jeong 2021).

With the ambivalent double definitions of English in policy documents English teachers also exhibit ambivalent perspectives on the language and ideal teaching model (Eriksson 2019; Forsberg, Mohr, and Jansen 2019; Llurda and Huguet 2003; Colmenero and Lasagabaster 2020). For example, through their questionnaire distributed to English teachers in Germany and Sweden, Forsberg et al. (2019) found that teachers focus on communicative competence, for which, they 'do not claim that the goal is native-like "correct English"” (51). However, these teachers also express contradictory views, such as their belief that grammar and pronunciation of American and British English are correct; their preference for using British or American English for their teaching; their consideration of American English as a “"neutral” or "non-specific" variety” (53).

\section{Method}

\section{Participants: Pre-service primary school teachers from Spain and Sweden in an}

\section{ELF context}

Participants were 71 students in primary school teacher education at a Spanish university and a Swedish university, who submitted their survey answers and informed written consent for participation: 22 females and 8 males were from Spain; 40 females 
and 1 male from Sweden. English was one of the school subjects they would teach. At the online platform offered by eTwinning, the EU online teachers' network (etwinning.net), the students from both countries engaged in small-group virtual collaboration for 4 weeks as part of their English coursework, to make group presentations on diverse culture themes. Thus, they were ELF users in terms of how and with whom they used English as we defined earlier. Both Spanish and Swedish students evaluated their English level similarly; where ' 1 ' meant 'very poor' and ' 6 ' meant 'very good', the average rating was $4.4(\mathrm{SD}=0.8)$. However, the two groups were heterogeneous in several ways, including their ages, how they use English, the research orientations of their own lecturers (i.e., the authors of this paper). The specifications of this heterogeneity between the two groups are presented in the findings and discussion section, in connection to discussing relevant findings.

\section{Data collection and analysis}

Data was collected via a Google Form survey, distributed right after the eTwinning collaboration. Besides requesting demographic information, the survey involved items about how participants used English, attitudes towards oneself and partner students as English users, and the impact of international contact on their own attitudes, in the forms of the 1-6 Likert scale, one-word description, one-sentence description and openended question (see the Findings and discussion section). We analysed participants' ELF user attitudes with three attitudinal tendencies adopted from Sung (2018), namely, 'positive ELF orientation', 'NS-centricity' and 'ambivalence'. Centrally, we observed in what ways students from the two countries were similar or different in their ELF user attitudes. For presenting answers verbatim, we coded participants with their nationalities and numbers indicating the arrival order of their responses, such as 'Swedish 1' or 'Spanish 20'. 


\section{Findings and discussion}

\section{Convergence in positive ELF orientation}

In terms of their thoughts about English, their own and partner students' English, and the impact of international contact on their attitude towards English, Spanish and Swedish students alike tended to exhibit positive ELF orientation (see Table 1).

First, in their one-sentence answers to the open-ended question of why English is important, $60 \%$ of Spanish students $(\mathrm{N}=30)$ and $80 \%$ of Swedish students $(\mathrm{N}=41)$ showed positive ELF orientation, with high awareness of English as a medium for global communication. This finding is aligned with the findings of Curran \& Chern (2017), Sung (2018), Rahatlou et al. (2018), Lai (2020), Jaramillo et al. (2020), and Takahashi (2017). Only one Spanish student was classified into being NS-centric with her answer '[because] I want to live in an English-speaking country' (Spanish 35) while answers like '[because] I use [English] a lot in my daily life' (Swedish 21), or '[because] I want to be an English teacher' were regarded as ambivalent. Some statements classified into positive ELF orientation are:

'[English] allows me to communicate with people all over the world and because nowadays it is the base of everything.' (Spanish 20)

'It's important to make sure that you can talk and make you understood by others who do not speak your language.' (Swedish 31)

Second, positive ELF orientation was also dominant in participants' attitudes towards their own and partner students' English. We requested participants to provide one most suitable adjective for describing their own English (one question) and their partners' English (another question). As their lecturers, we authors confirm that all our participants learnt English as a second language. In view of this background, we coded the adjectives they used into 'positive ELF orientation', 'NS-centricity', or 
'ambivalence'.

As presented in Table 1, slightly more than half of both Spanish (56.7\%) and Swedish students (56.1\%) were positive about their own English. Used adjectives were '(very) good', 'efficient', 'clear', 'understandable', 'comprehensible', 'nice', 'adequate', 'fluent', 'functional', and 'confident'. Taking Spanish and Swedish students altogether, some were negative (26.4\%) or ambivalent (17.2\%) in their view of their own English. Answers classified into NC-centricity (i.e., negative) include 'nervous', 'peculiar', 'uncertain', 'insecure' and, 'funny', while those into ambivalence include 'manageable', 'improvable', 'improving', and 'interesting'. Meanwhile, both Spanish (90\%) and Swedish students (82.9\%) were mostly positive towards partner students' English, using adjectives, such as 'understandable', 'intelligible', 'comfortable', and 'interactive', aligned with the intelligibility principle in using English as a lingua franca (see Jenkins 2007). However, some positive adjectives like 'perfect' and 'accurate' were classified into NS-centricity, together with the negative adjectives, 'sluggish' and 'worse' while 'typical' by one Swedish student was regarded as being ambivalent.

One more aspect of using English with the dominance of positive ELF orientation was the impact of international contact on one's attitude towards English. In their answers to the open-ended question, 'in what ways do I think eTwinning (i.e., international contact) has influenced my perception and attitude towards English and its users?', $86.7 \%$ of Spanish and $87.8 \%$ of Swedish students showed positive ELF orientation. We also included some students in positive ELF orientation, whose answers indicated that they had already been positive about English as a lingua franca even before the eTwinning project through their previous international experiences. Below are two students' verbatim answers with positive ELF orientation: 
'Through this project [international contact], I have realised that English is not a mere tool for learning or even a simple subject, but something bigger that allows us to effectively communicate with people from other parts of the world. We have managed both to perfectly understand our Swedish partners and to make ourselves understood, thus establishing a proper communication that has allowed us to collaborate and decide on the tasks, which was the main aim of the project.' (Spanish 36)

'I think that [eTwinning] has helped me not to think negatively about my own English skills. I can speak English better than I thought and I have understood the goal is not making my pronunciation perfect all the time but that I can make myself understood for other English speakers. It was fun to communicate with Spanish students and we could share different experiences between our countries.'

(Swedish 11)

A minority of participants provided somewhat negative answers that we decided to classify into NS-centricity. One of them was, 'I became surprised at how difficult it was to understand Spanish students' (Swedish 46).

Table 1. Aspects towards which both Spanish and Swedish students tended to have positive orientation.

\begin{tabular}{ccccc}
\hline \multirow{2}{*}{ Aspects } & Countries & \multicolumn{3}{c}{ Attitudes (\%) } \\
\cline { 3 - 5 } & & $\begin{array}{c}\text { Positive } \\
\text { ELF } \\
\text { orientation }\end{array}$ & $\begin{array}{c}\text { NS- } \\
\text { centricity }\end{array}$ & Ambivalence \\
\hline Reasons why English is & Spain & 60.0 & 3.3 & 36.7 \\
important & Sweden & 80.5 & 0 & 19.5 \\
One's own English & Spain & 56.7 & 33.3 & 10.0 \\
& Sweden & 56.1 & 19.5 & 24.4 \\
Partner students' English & Spain & 90.0 & 10.0 & 0 \\
Impact of international contact & Sweden & 82.9 & 14.6 & 2.4 \\
on attitudes towards English & Spain & 86.7 & 13.3 & 0 \\
\hline & Sweden & 87.8 & 12.2 & 0 \\
\hline
\end{tabular}

Note. Spanish students $(\mathrm{N})=30 \&$ Swedish students $(\mathrm{N})=41$

\section{Divergence in NS-centricity}

The two participant groups diverged into more and less NS-centred tendencies in their 
answers to two Likert questions $(1=$ strongly disagree $\& 6=$ strongly agree $)$. First, to the question, 'To me, English is a foreign language as it is the national language of some countries like the UK and the US', Spanish students (mean rank $=4.45$ ) agreed with the statement significantly more than Swedish students (mean rank $=2.98$ ) as seen in Figure 1: Mann Whitney $\mathrm{U}$ test: $\mathrm{U}=361, p=0.003$. Second, to the question, 'I want to sound like an English native speaker', as presented in Figure 2, Spanish students (mean rank $=5$ ) agreed with the statement significantly more than Swedish students (mean rank =2.58): Mann Whitney $\mathrm{U}$ test: $\mathrm{U}=195, p=0$

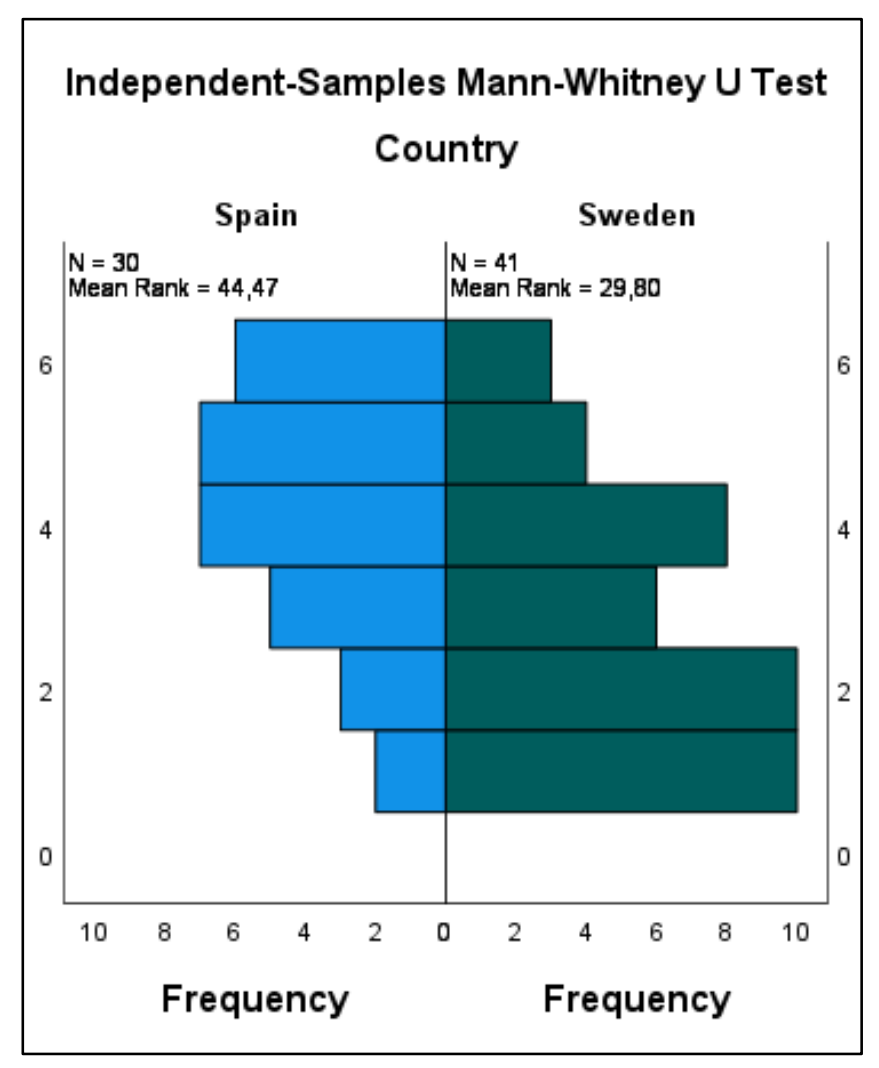

Figure 1. Question: "For me, English is a foreign language as it is the national language of some countries like the UK and the US" ( 1 = strongly disagree \& $6=$ strongly agree) 


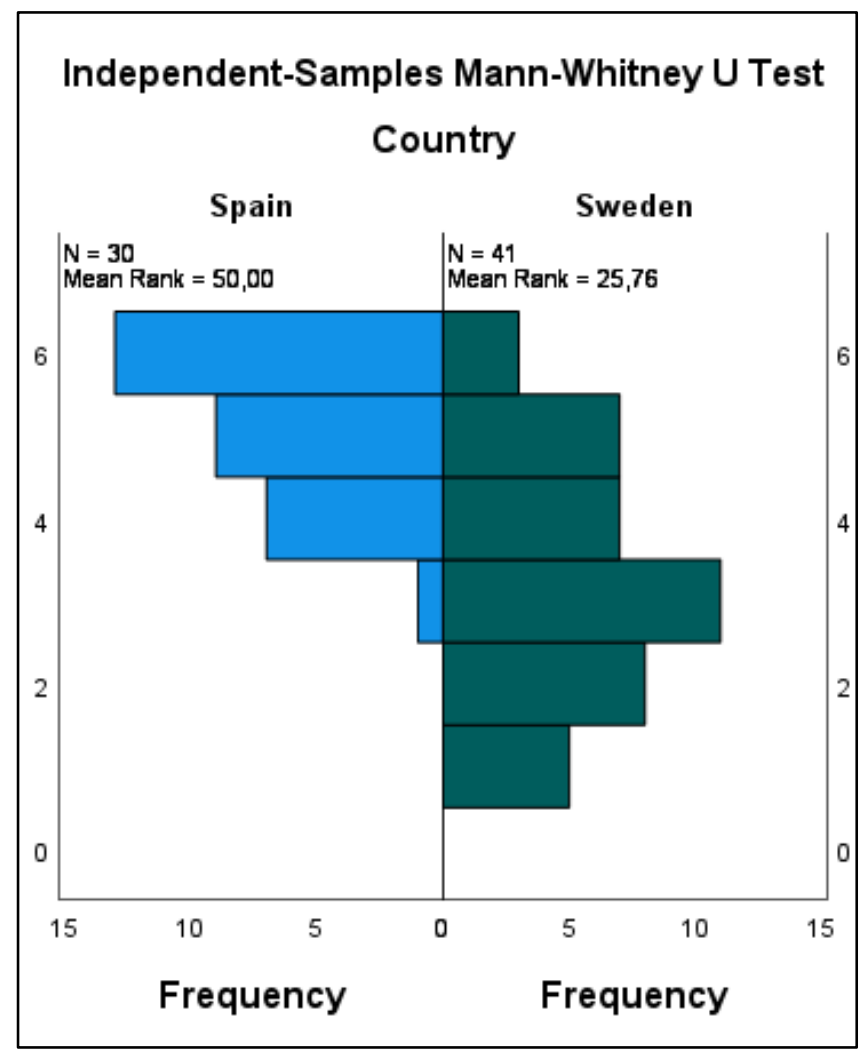

Figure 2. Question: "I want to sound like an English native speaker" (1 = strongly disagree $\& 6=$ strongly agree)

Since the two student groups from Spain and Sweden were heterogeneous, to understand the above results, we considered their ages, international experiences, how they use English, and the orientations of their own eTwinning instructors (i.e., the authors). As indicated in their ages $(19-29$ years old, mean age $=19.87)$, most Spanish students graduated from upper-secondary school recently, and thus they might still be aligned with their upper secondary English teachers' views, which were likely to be NScentred (Eriksson 2019; Forsberg et al. 2019; Llurda and Huguet 2003; Colmenero and Lasagabaster 2020), more than Swedish students who were much older (19-46 years old, mean age $=27.22)$ and had years of life experience after upper secondary school education. In fact, there was a negative correlation between respondents' ages and their ratings for "I want to sound like an English native speaker": non-parametric Spearman's 
rho $=-.482, p=0$.

Moreover, many more Swedish students (80.5\%) than Spanish students (33.3\%) use English for international communication at work or for leisure time activities, such as gaming or travelling, which can possibly be a reason for Swedish students being less NS-centric than Spanish students. As reported earlier, many Swedish students had developed positive ELF orientation before the eTwinning collaboration through their previous experience of using English for international communication. Swedish 1, for example, remarks, 'I have used English so much before with both native and non-native speakers', and Swedish 2 notes that the eTwinning project did not impact her attitude that much because she was already 'used to speaking with non-native English speakers.' Meanwhile, around half of Spanish students (56.7\%) used English among themselves in their university context, for the purpose of improving language skills, which might not help Spanish students that much to change their view of English shaped through their earlier education that probably played an influential role in shaping their language attitudes (Busse 2017).

One more factor for the different degrees of NS-centricity between Spanish and Swedish students' attitudes can be their own instructors (Kaçar 2021). Sánchez Ruiz, the Spanish instructor, has an English as a foreign language (EFL)/bilingual perspective (Pérez-Segura, Sánchez Ruiz, González-Calero, and Cózar, 2020) while one of the two instructors of Swedish students, Jeong, explicitly rejects native speakerism with her ELF/Global Englishes orientation (Jeong 2021). During Jeong's phonetics module that Swedish students took just before doing eTwinning, they were encouraged to critically reflect on native speaker norms in English education. Perhaps, this had also made an impact on Swedish students' perception as indicated by some students. For example: 
'Overall, phonetics and eTwinning changed my attitude towards people who speak English with different accents. I now listen carefully to what people say, and if I don't understand I will ask again.' (Swedish 46)

\section{Overall tendency: being ambivalent, after all}

Despite the ELF orientation of one lecturer of Swedish students (i.e., Jeong), the overall approach to English education that both Spanish and Swedish students learned to take could be regarded as a traditional EFL one, as the English courses in both countries taught the students to adopt the CEFR for their English education: that is, the preservice teachers learned to use the CEFR as guidelines for their future teaching. This seemed reflected in the participants' overall attitudes, which we eventually coded into one of positive ELF orientation, NS-centric and ambivalent through examining their answers about all six aspects of:

- reasons why English is important

- perception of one's own English

- perception of partner students' English

- impact of international contact on their attitude towards English and its users

- whether English is a foreign language as it is a national language of certain countries, like the UK and the US

- whether to want to sound like an English native speaker

We classified individuals into positive ELF orientation or NS-centricity when they have one of the two attitudinal tendencies consistently in all aspects, or in four to five aspects with being ambivalent for the rest. Otherwise, we sorted other combinations into ambivalence as then they showed mixed or contradicting attitudes evidently. Table 2 presents that $12.7 \%$ of 71 participants showed positive ELF-orientation and $18.3 \%$ NS- 
centricity, where, as shown in the previous sections, Swedish students tended to be more positively ELF oriented while Spanish students more NS-centric. The prevalent tendency in their overall ELF user attitudes of both Spanish and Swedish students was ambivalence (69\%) with different combinations. For example, a participant stated English is important because it is an international communication tool, her own English 'satisfactory' and partner students' English 'comprehensible', in addition to noting that international contact positively influenced her own attitude towards English and its speakers. Nevertheless, she strongly agreed that she wanted to sound like an English native speaker. On the other hand, another participant was somewhat ambivalent in his answers overall, stating 'learning' for his own English and 'sharing' for partner students' English, and 'because I use it in university' for why English is important, and somewhat agreed to want to sound like a native speaker. Thus, as their overall attitude, our participants manifested the pervasive tendency among ELF users that previous research witnesses - being ambivalent (Sung 2018; Jenkins, 2007; Takahashi, 2017; Rahatlou et al. 2018; Jaramillo et al. 2020; Lai, 2020).

Table 2. Overall ELF user attitude

\begin{tabular}{lccc}
\hline & \multicolumn{3}{c}{ Attitudes (\%) } \\
\cline { 2 - 4 } & $\begin{array}{c}\text { Positive ELF- } \\
\text { orientation }\end{array}$ & NS-centricity & Ambivalence \\
\hline Spain $(\mathrm{N}=30)$ & 3.3 & 36.7 & 60.0 \\
Sweden $(\mathrm{N}=41)$ & 19.5 & 4.9 & 75.6 \\
Total $(\mathrm{N}=71)$ & 12.7 & 18.3 & 69.0 \\
\hline
\end{tabular}

\section{Conclusion}

To recap, our study investigated the attitudes of two pre-service teacher cohorts from Spain and Sweden towards several aspects related to English and its users. We defined our participants as 'ELF users' in terms of how and with whom they used English, and 
hence their attitudes as 'ELF user attitudes'. We are never able to claim that our participants represent the whole population of European ELF users; but we believe they could showcase some 'typical' Euro ELF users as well as 'ordinary' future teachers of new Euro ELF user generations.

Besides noting that our findings are largely aligned with the studies on ELF user attitudes around the globe (Sung 2018; Jenkins 2007; Takahashi 2017; Rahatlou et al. 2018; Jaramillo et al. 2020; Lai 2020), we conclude that the ambivalence of our participants' attitudes seems to mirror the ambiguity of national language policies for English education. Such ambiguity in policy documents emerges from the double definitions: on the one hand, English as an internal communication tool; and on the other, it as a foreign language. These two definitions of English are likely incompatible with each other in terms of setting the goals of teaching and learning, as we discussed earlier. We believe that this is a critical issue that needs to be addressed, particularly for (future) primary school teachers like our participants, who themselves use English mainly for international communication, and who will teach English to young learners whose needs for using English as a contact language will probably be even bigger, given the ever-increasing role of the language as a global communication tool.

Without a doubt, more fundamental changes should be made to policy documents including the CEFR Companion Volume (if it continues to be used for English education). While urging for revision to language policies for clarity, consistency, and responsiveness to learners' needs, based on our own and other studies (e.g., ChacónBeltrán 2021; Delgado-Marín 2018; Dewey and Pineda 2020), we wish to suggest what university teaching can do for equipping pre-service teachers with criticality and discernment for making decisions in their own teaching contexts. First, pre-service teachers should be well-informed about how the two concepts of English as a foreign 
language and as a lingua franca differ and be encouraged to discuss what can be the pedagogical consequences of taking one over the other in their teaching practice. Such discussions should be as open-ended as possible so that they can be the starting point of reflective thinking. Second, including international communication and collaboration as part of university education can help pre-service teachers widen their views of English and its users. The impact of such ELF experience within teacher education can be even greater, if activities during international collaboration include reflective, meta-cognitive observations of what language skills are beneficial in real-life English. Finally, instead of unproblematically presenting policy documents as what teachers are obliged to follow entirely, teacher educators can help their students critically engage with such documents, scrutinizing and problematizing the content in view of their own and their future learners' needs.

\section{Acknowledgements}

We authors are very thankful to our student participants for doing an eTwinning project with us and providing their answers for this study. We also thank each other for our collaboration through which we have learned from each other.

\section{References}

Busse, V. (2017). "Plurilingualism in Europe: Exploring attitudes toward English and other European languages among adolescents in Bulgaria, Germany, the Netherlands, and Spain." The Modern Language Journal 101(3): 566-582. doi:10.1111/modl.12415.

Caraker, R. (2016). "Spain and the context of English language education." Research Bulletin, 92: 23-35.

Chacón-Beltrán, R. (2021). “Attitudes towards English as a lingua franca among prospective EFL teachers in Spain.” In Intercultural competence past, present and future: respecting the past, problems in the present and forging the future, 
edited by M. D. López-Jiménez and J. Sánchez Torres, 165-184. Singapore: Springer.

Council of Europe ([2001] 2020). "Common European Framework of Reference for Languages: Learning, teaching, assessment - Companion volume." Strasbourg: Council of Europe Publishing, available at www.coe.int/lang-cefr.

Cogo, A. (2010). "Strategic use and perceptions of English as a lingua franca." Poznań Studies in Contemporary Linguistics 46 (3): 295-312. doi:10.2478/v10010-0100013-7.

Cogo, A. and Jenkins, J. (2010). "English as a lingua franca in Europe: A mismatch between policy and practice." European Journal of Language Policy 2(2): 271293. doi:10.3828/ejlp.2010.16.

Colmenero, K. and Lasagabaster, D. (2020). “Enclosing native speakerism: students', parents' and teachers' perceptions of language teachers." Journal of Multilingual and Multicultural Development. doi:10.1080/01434632.2020.1865384.

Curran, J. E. and Chern, C. L. (2017). "Pre-service English teachers' attitudes towards English as a lingua franca." Teaching and Teacher Education 66: 137-146. doi:10.1016/j.tate.2017.04.007.

Delgado-Marín, C. (2018). "Interlanguage as the sole common space for mutual understanding in the bilingual classroom: Non-native teachers in bilingual educational programs in Spain.” In (Se) construire dans l'interlangue: perspectives transatlantiques sur le multilinguisme edited by F. BonnetFalandry, S. Durrans and M. Jones (Dir.), 49-60. Villeneuve d'Ascq cedex: Septentrion.

Dewey, M. and Pineda, I. (2020). "ELF and teacher education: attitudes and beliefs." ELT Journal , 74(4): 428-441. doi:10.1093/elt/ccaa047.

Eriksson, L. E. (2019). “Teachers' and students' attitudes and perceptions toward varieties of English in Swedish upper secondary school." In Rapport från ASLAsymposiet i Karlstad, 12-13 april, 2018. edited by B. L. Egeland, T. Roberts, E. Sandlund, and P. Sundqvist. 207-233. Karlstad: Karlstad University

Forsberg, J., Mohr, S., and Jansen, S. (2019). "The goal is to enable students to communicate: Communicative competence and target varieties in TEFL practices in Sweden and Germany." European Journal of Applied Linguistics 
Hult, F. M. (2012). "English as a transcultural language in Swedish policy and practice." TESOL Quarterly 46 (2): 230-257. doi:10.1002/tesq.19.

Hynninen, N. (2014). "The Common European Framework of Reference from the perspective of English as a lingua franca: What we can learn from a focus on language regulation.” Journal of English as a Lingua Franca 3(2): 293-316. doi:10.1515/jelf-2014-0018.

Jaramillo, M. G. L., Dávila, A. M., and Jarquín, E. V. E. (2020). "English as a lingua franca: Perspectives from international MA TESOL students in the United States." Universal Journal of Educational Research 8(4): 1605-1619.

Jenkins, J. (2007). English as a lingua franca: Attitude and identity. Oxford: Oxford University Press.

Jeong H. (2021). "Global English in the Workplace: Introducing the Concepts of 'Workplace English as a Lingua Franca' (WELF), and 'Successful WELF Users'.” In: A. Henry and Persson Å. (eds) Engaging with Work in English Studies. edited by A. Henry and Å. Persson, Palgrave Macmillan: Cham. https://doi.org/10.1007/978-3-030-69720-4_9

Lai, M. L. (2020). "English as a lingua franca: Rhetoric or reality? Attitudes of prospective English teachers in Post-colonial Hong Kong." Asian Studies Review 44(3): 494-514. doi:10.1080/10357823.2019.1693977.

Llurda, E. and Huguet, A. (2003). "Self-awareness in NNS EFL Primary and Secondary School Teachers." Language Awareness 12(3): 220-233. doi:10.1080/09658410308667078.

McNamara, T. (2011). "Managing learning: Authority and language assessment." Language Teaching, 44(4): 500-515. doi:10.1017/S0261444811000073.

Pérez-Segura, J. J., Sánchez Ruiz, R., González-Calero, J. A., and Cózar, R. (2020). "The effect of personalized feedback on listening and reading skills in the learning of EFL." Computer Assisted Language Learning, 33:1-23. https://doi.org/10.1080/09588221.2019.1705354

Pew Research Center (April 2020). "Most European students learn English in school [Report].” https://www.pewresearch.org/fact-tank/2020/04/09/most-europeanstudents-learn-english-in-school/

Rahatlou, B. M., Fazilatfar, A. M., and Allami, H. (2018). "English as a lingua franca in Iran: An attitudinal investigation into the in-service teachers." Cogent Education, 5(1): 1-19. doi:10.1080/2331186X.2018.1499215. 
Reichelt, M. (2006). "English in a multilingual Spain.” English Today, 22(3): 3-9. doi:10.1017/S0266078406003026.

Rose, H., McKinley, J., \& Galloway, N. (2020). “Global Englishes and language teaching: A review of pedagogical research.” Language Teaching, 54(2)157189. doi:10.1017/S0261444820000518.

Seidlhofer, B. (2020). "English as a lingua franca in the European context." In, The Routledge handbook of World Englishes ( $2^{\text {nd }}$ ed) edited by A. Kirkpatrick, 389407. Oxen: Routledge.

Siqueira, S. (2020). "ELF with EFL: what is still needed for this integration to happen?" ELT Journal 74(4):377-386. doi:10.1093/elt/ccaa038.

Sung, C. C. C. 2018. "Investigating perceptions of English as a lingua franca in Hong Kong: The case of university students." English Today 133(34): 38-44. doi:10.1017/S0266078417000293.

Takahashi, R. (2017) “Attitudes of Japanese learners and teachers of English towards non-standard English in coursebooks." Changing English 24(1): 42-52, doi:10.1080/1358684X.2016.1228444. 